\title{
IMPROVEMENT OF MICROLEARNING WITH HELP OF LEARNING ANALYTICS IN ENTERPRISES
}

\author{
Uldis Zandbergs $^{1}$, Janis Judrups ${ }^{1}$, Elina Plane ${ }^{1}$, Raitis Uscins ${ }^{2}$ \\ ${ }^{1}$ Baltic Computer Academy Ltd, Latvia; ${ }^{2}$ Tet, Latvia \\ uldis.zandbergs@bda.lv, janis.judrups@bda.lv, elina.plane@bda.lv,uscins@tet.lv
}

\begin{abstract}
Modern organisation environment is characterised by constant change, which creates the need for the employees to constantly acquire new knowledge and learn new skills to retain a competitive advantage. Professional learning in such an environment needs to be adjusted to become fast-paced, chunk-sized and selfdirected for relevancy and efficiency. COVID-19 pandemic has enhanced the problem, making traditional classroom training unavailable and the efficiency of self-directed learning hard to evaluate. Microlearning approach provides small sized development opportunities for employees without spending lots of time outside their actual work and the opportunity to apply the new knowledge almost immediately to work situations. Learning analytics helps evaluate the need and effectiveness of microlearning, it is useful in training situations that want to predict and manage the success of their students, but is harder to apply in professional environment because of how indicators for learning results translate to success in work situations. The paper describes the initial results of a case study of development and implementation of work-related microlearning modules and training tests and the use of learning analytics to predict the training results based on progress and to supply the managers with information for decision making. In this case participation in microlearning activities and positive attitude towards them was linked to increased test scores suggesting that it can be used for predicting employee success in work situations.
\end{abstract}

Keywords: microlearning, learning analytics, competence development, non-formal education.

\section{Introduction}

In a modern business environment, there are two markets that the businesses need to compete in. One is a product market where businesses offer their products or services to the customers and the other is employment market where businesses compete to acquire employees to produce their products or services. In the employment market there is a shortage of employees because the skills that the employees need to possess are constantly changing and often the set of skills that is required is companyspecific [1]. Re-training the existing employees is a superior option to hiring new ones. Managers of various organisations recognise the need for their employees to learn new skills, but they are also under pressure to provide learning opportunities that translate into business results. Self-regulated, workrelated, just-in-time learning is encouraged [2].

Microlearning is an approach to learning that is applicable to business environment and follows a strategy to achieve a learning goal by using small scale (bite-size) learning opportunities. Microlearning can provide the right amount of information at the right time to the right person at the right level of detail [3]. Microlearning is a good option to provide learning opportunities in business environment. In addition, the global pandemic (COVID-19) has forced many training providers to adjust to the situation. Training without direct contact is preferred.

Microlearning is a trend in learning that is already covered in scientific research, but it has a tendency to mature and develop into mainstream research issue [4]. Microlearning is associated with elearning, internet and mobile technologies [5]. Microlearning is a more efficient approach than traditional classroom training because of increased involvement of participants, better retention of concepts, increased motivation of participants, improved convenience for participants [6;7].

Microlearning addresses issues that are relevant for a typical learner today. A learner tends to be distracted and impatient because of the technologies that are available for receiving new information needed for the completion of tasks [8]. Microlearning may have limitations when completely new knowledge is acquired, but has value when providing insight into a new topic or improving on existing knowledge [9].

When applying microlearning in a business environment, these characteristics are important: content should be aligned with a small goal, content should be divided in small, easy to process chunks, care should be taken not to overwhelm and confuse the learning, development of microlearning content can be expensive and time consuming [10]. From the content point of view microlearning consists of: 
information presented in small chunks and in various forms (e.g., text, images, audio, video), tests and quizzes to measure progress, gaming elements included to improve the learning process [11].

Microlearning is often provided in a learning management system (LMS) [12]. A LMS provides an opportunity to implement continuous learning in a workplace environment and the technical means to implement the desired microlearning functionality. A LMS also facilitates the gathering of data that are needed for the learning analytics (LA).

Learning analytics is the measurement, collection, analysis about learners to optimise learning [13]. LA has evolved because of the ability to use Big Data. LA is used to improve learning opportunities that are provided based on data gathered about the learning process [14]. LA has been used at formal higher education institutions to improve the learning. However, their focus is on retaining learners and improving the training courses provided [15]. Professional LA is a subdiscipline of LA that is concerned with how LA can be applied to learning of professionals in a business environment [16]. It includes not only the analysis of data about learning but also links this information to the business goals. Learning analytics (LA) is a multidiscipline field that uses the ideas from learning science, computer science, information science, educational and data mining and artificial intelligence [17; 18]. As microlearning is often implemented as e-learning, the data it produces can be used for the analysis and decision making about the use and improvement of microlearning content and the application at a workplace.

LA uses theoretical models that explain how data gathered during training can be used to improve the training [19]. There are already existing models explaining the process of learning. The main topics these models describe are selection of data for analysis with a logical justification provided, processing and analysis of data gathered, use of data gathered for the decision making. LA is important in the current learning environment because of availability of options for learning and the confusion it may create, availability of tools and methods for data analysis, diminishing numbers or potential learners that training providers compete for, difference between the content of education provided and the training needs identified by the employers [20].

LA is used by learners and trainers that are interested in the individual progress and results of training process as opposed to administrators and decision makers, who are interested in data that provide information on a larger scale [13]. The later groups are more interested in academic analytics that provides information at a scale of a whole educational institution [21].

The goal of this paper is to explore how microlearning and learning analytics can be used together to improve training of employees in a company. This approach will improve the ability of the employees to reach business goals. The application of both microlearning and learning analytics in a specific business environment is the innovative approach that is presented in the case study.

\section{Materials and methods}

A case study has been performed about organising training by applying microlearning principles and using LA to measure the progress of learning at an ICT company. A model of learning process has been developed based on the theory of learning and the needs identified by the company.

Four microlearning modules have been developed over a period of 1 month using H5P interactive content technology, each 4 to 6 minutes in length and consisting of 1) 4 main interactive training videos with practical exercises and quizzes and 2) 5 graphical best practice work aids. The use of training videos and work aids was awarded a set number of credit points as a measurement of participation to be used for learning analytics. Partial use of training video was awarded 1 point, full use of training video - 2 points, use of work aid - 1 point. A total of 13 points could be received for full participation of all training elements.

A final competence evaluation test with 5 multiple choice questions emulating possible real work problems was developed corresponding to the training material and offered to the participants regardless of their participation in training. The results of the test were compared to the score of the participation in the training.

A satisfaction survey (see Table 1) was conducted, and it contained 3 main questions that were measured in 5-point scale each (from 1 (strongly disagree) to 5 (strongly agree)).

- Do you expect the training elements to be useful in work situations? 
- Do you intend to reuse the training materials?

- Is this a better approach to training than previously used?

The survey results were compared to the participation in training and the final test result.

The microlearning modules, the competence evaluation test and the survey were all implemented in Moodle learning management system.

As the company management expressed concerns about implementing a new kind of training, an initial pilot group of 16 participants was selected to participate as a proof-of-concept principle. In case of success training for a larger group of employees $(\mathrm{N}=100)$ is planned. The participants were informed that this was going to be the new approach to training in the company and they were invited to use all the available microlearning modules. The participation in training was not mandatory, but the final test was mandatory, and the participants were informed about the minimum result required to pass the test (75\% of correct answers). The training was conducted during 3 weeks in February 2021, although the time spent by each participant was less than 1 hour.

A research question was raised: will the more thorough participation in training and a more positive response in the survey predict higher final test results for the participant?

\section{Results and discussion}

A general model for development of microlearning module with several individual elements was developed based on the general idea that training of the employees should be goal-oriented and produce work results that can be measured by the supervisor and predicted by the data gathered based on the participation in training. The model is presented in Figure 1.

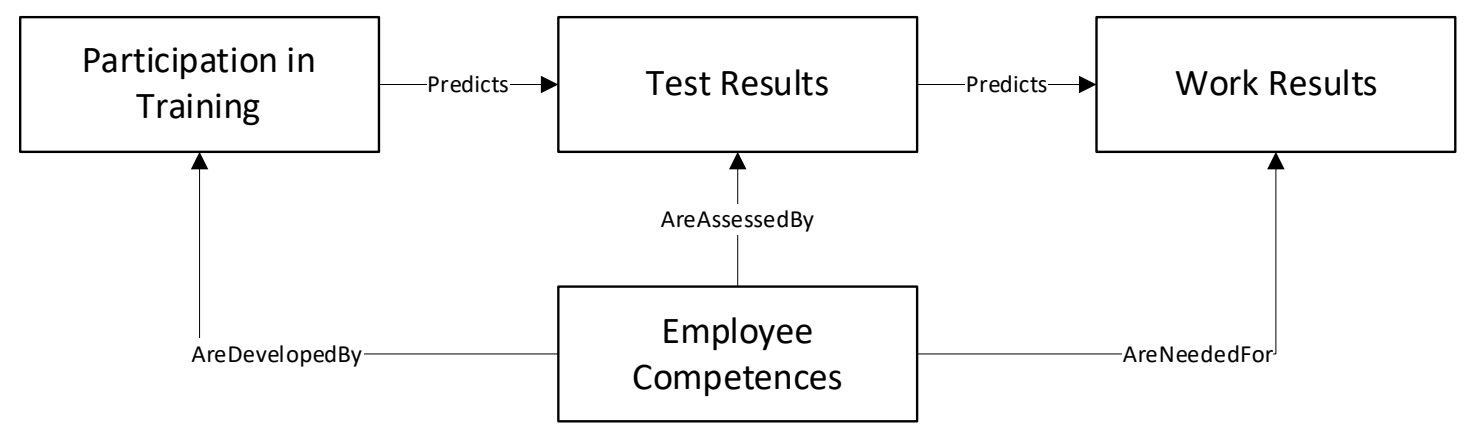

Fig. 1. General model for learning analytics

The model assumes that the work results will be dependent on the competences possessed by the employee. Competences are a characteristic of an employee that should be possessed by the employees for the managers to be able to predict work results [22-23]. These competences should be viewed as indicators for employee development needs [24]. For successful training measurement of work results and the content of training solution (e.g., microlearning modules in this case) should be aligned with the content and description of the required employee competences [25-26].

The microlearning modules with the interactive elements and the final test of training results were developed based on the required competences for the desired work results based on typical mistakes that are necessary to avoid. The progress of the training process was captured, and the results of the final test were recorded (see Table 1).

In Table 1 there is a summary of 5 main characteristics of the training process that were captured for the use in LA; participation in interactive videos (max score 8 points), participation in interactive videos plus use of work aids (max score 13 points), number of attempts at final test (max 3 attempts), final test result (max 10 points, passing grade 7.5 points), and the result of satisfaction survey with training provided (max 15 points).

Based on the participation score for interactive videos, we divided the participants into two groups: 1) Group A had 100\% completion of all the content of interactive videos, 2) Group B had only partial participance (50\% of material completed on average). 
Summary of training results

Table 1

\begin{tabular}{|c|c|c|c|c|c|}
\hline Employee & $\begin{array}{c}\text { Score for } \\
\text { interactive videos }\end{array}$ & $\begin{array}{c}\text { Score for interactive } \\
\text { videos + work aids }\end{array}$ & $\begin{array}{c}\text { Test } \\
\text { attempts }\end{array}$ & $\begin{array}{c}\text { Final test } \\
\text { result }\end{array}$ & Survey \\
\hline D1 & 3 & 4 & 3 & 4.33 & 15 \\
\hline D2 & 2 & 3 & 0 & 0.00 & 13 \\
\hline D3 & 8 & 13 & 2 & 10.00 & 15 \\
\hline D4 & 8 & 13 & 1 & 8.00 & 12 \\
\hline D5 & 8 & 13 & 1 & 8.67 & 4 \\
\hline D6 & 8 & 9 & 1 & 8.50 & 13 \\
\hline D7 & 4 & 4 & 0 & 0.00 & 14 \\
\hline D8 & 5 & 6 & 2 & 7.50 & 15 \\
\hline D9 & 8 & 13 & 1 & 7.50 & 11 \\
\hline D10 & 8 & 13 & 1 & 9.50 & 14 \\
\hline D11 & 6 & 8 & 1 & 7.50 & 8 \\
\hline D12 & 4 & 5 & 0 & 0.00 & 9 \\
\hline D13 & 8 & 8 & 1 & 9.00 & 9 \\
\hline D14 & 8 & 13 & 1 & 9.00 & 15 \\
\hline D15 & 8 & 12 & 1 & 7.50 & 14 \\
\hline D16 & 8 & 13 & 2 & 10.00 & 15 \\
\hline
\end{tabular}

Group A also used more additional work aids. On average Group A used $92.3 \%$ of all the available training content including interactive videos and work aids. Group B used only $38.5 \%$ of all the available training content on average. Group A was more successful in the final test. On average Group A scored $87.7 \%$ out of $100 \%$ in the final test. Group B scored only $32.2 \%$ on average (see Figure 2). Note that some of the employees in Group B did not attempt the test at all and were assigned a score of zero. We think these employees expected low results and did not want them to go on record. We think it was safe to interpret these cases as failure to reach a passing score within a given time frame.

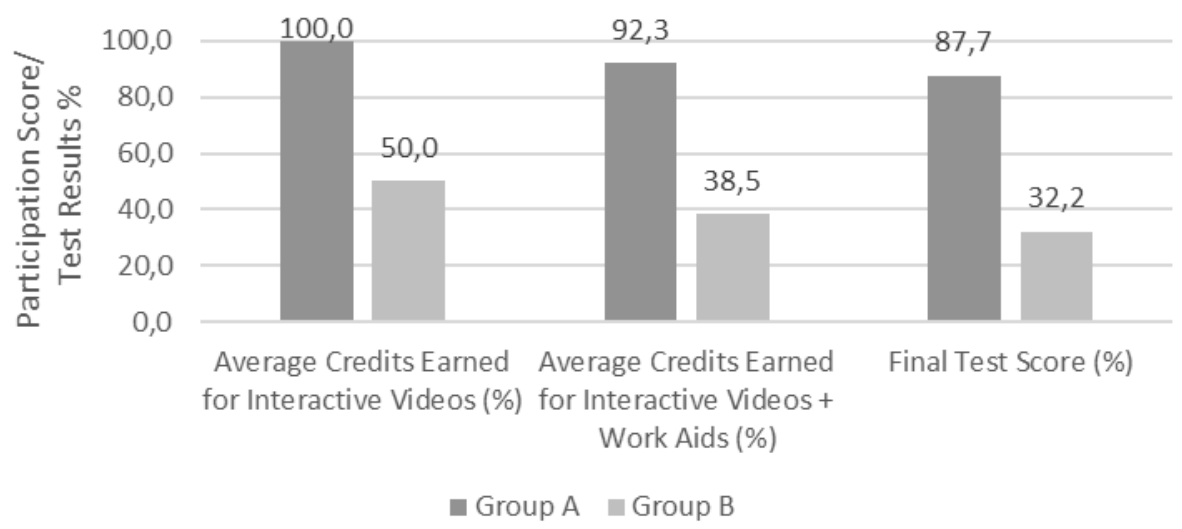

Fig. 2. Comparison of test results based on participation in microlearning

This suggests that participation in interactive videos may be used as a preliminary indicator of success in the test, but more statistical data should be gathered for the definite proof. The average indicators for participation in training and the expected final test results may vary for a larger group of participants. If the test results are to be used by managers to allow the successful employees to perform their work assignments, then an indicator of participation in training that can be received earlier than the test results should be helpful in decision making.

The survey was used to measure the opinion of participants, if use of microlearning modules could have been influenced negatively by the form of training. The average result was 12.25 out of 15 (see Table 1). Participants also provided additional comments on why they liked the training, for example, shorter length of the training, ability to train on their own time, ability to train remotely and ability to use again the materials provided. This corresponds to the main benefits of microlearning reported by other authors $[13 ; 16]$ The main complaint was that there were too many tests included in the 
microlearning elements. This was due to limited range of interactive elements used. During each of the 4 interactive videos the participants were asked to evaluate if they feel like they have understood the topic and were also presented with multiple choice questions designed to be an additional learning experience. These questions were probably interpreted as additional "tests" by the employees and received some negative feedback, because they were associated with possible negative consequences for failing the actual final test.

\section{Conclusions}

In the situations when providing a traditional classroom training is not feasible because of the scope of training, the logistics of training organization, and the global situation with COVID-19 pandemic when reduction of direct contact is recommended, microlearning in form of e-learning is beneficial. The following conclusions have been drawn:

1. Participants who used more of the training materials provided ( $100 \%$ of interactive videos and $92.3 \%$ of all training materials used) received higher test results (87.7\% out of $100 \%$ as compared to $32.2 \%$ for the other group). Participation in microlearning can be used as an indicator to predict success in testing at the end of training.

2. Survey indicated that in general participants liked the microlearning experience (12.25 points out of 15). Participant attitude towards training materials was not the likely reason for not participating.

3. The results of the sample group of participants proved the concept that registered participation in microlearning can be used as an indicator for the success in testing, but to establish possible results thresholds a bigger sample of participants is required.

For further research it is necessary to continue the study by involving a larger number of participants in the microlearning experience at the ICT company. It was not possible to compare the test results with the actual work performance results during the case study. This is planned for the future, when the possible improvement in work performance based on the training conducted would be measured.

\section{Acknowledgements}

The research leading to these results has received funding from the project "Competence Centre of Information and Communication Technologies" of the EU Structural funds, contract No. 1.2.1.1/18/A/003 signed between the IT Competence Centre and the Central Finance and Contracting Agency, Research No. 1.4 "Development of a modular Personnel Management Solution (PPR) based on smart technologies".

\section{References}

[1] Cedefop. Insights into skill shortages and skill mismatch: learning from Cedefop's European skills and jobs survey. Luxembourg: Publications Office. Cedefop reference series; No 106, 2018. [online] [21.03.2021] Available at: http://data.europa.eu/doi/10.2801/645011

[2] Littlejohn A. Learning and Work: Professional Learning Analytics. In: Lang, Charles; Siemens, George; Wise, Alyssa and Gasevic, Dragan eds. Handbook of Learning Analytics. Society for Learning Analytics Research, 2017. pp. 269-277.

[3] Emerson L. C., Berge Z. L. Microlearning: Knowledge management applications and competencybased training in the workplace. Knowledge Management \& E-Learning, 10(2), 2018, pp. 125-132.

[4] Leong K., Sung A., Au D., Blanchard C., A review of the trend of microlearning, Journal of WorkApplied Management, Vol. ahead-of-print No. ahead-of-print, 2020. DOI: 10.1108/JWAM-102020-0044

[5] Shail M. Using Micro-learning on Mobile Applications to Increase Knowledge Retention and Work Performance: A Review of Literature. Cureus. 11. 2019. 10.7759/cureus.5307.

[6] Giurgiu L. Microlearning an Evolving Elearning Trend. Scientific Bulletin. 22. 2017. DOI: $10.1515 /$ bsaft-2017-0003.

[7] Nikou S., Economides A. Mobile-Based micro-Learning and Assessment: Impact on learning performance and motivation of high school students. Journal of Computer Assisted Learning. 34. 2018. DOI: 10.1111/jcal.12240.

[8] Dontre A.J. The influence of technology on academic distraction: A review. 2020. DOI: $10.1002 / \mathrm{hbe} 2.229$ 
[9] Emerson L. C., Berge Z. L. Microlearning: Knowledge management applications and competencybased training in the workplace. Knowledge Management \& E-Learning, 10(2), 2018, pp. 125-132.

[10] Mohammed G.S., Wakil K., Nawroly S.S. The effectiveness of microlearning to improve students' learning ability. International Journal of Educational Research Review,3(3), 2018, pp. 32-38.

[11]Park Y., Kim Y. A Design and Development of micro-Learning Content in e-Learning System. International Journal on Advanced Science, Engineering and Information Technology. 8. 56. 2018. DOI: 10.18517/ijaseit.8.1.2698.

[12] Turnbull D., Chugh R., Luck J. Learning Management Systems: An Overview. 2019. 10.1007/9783-319-60013-0_248-1.

[13]Long P., Siemens G. Penetrating the Fog: Analytics in Learing and Education, Educause Review, 46 (5), 2011, pp. 31-40.

[14]Rienties B., Køhler Simonsen H., Herodotou C. Defining the boundaries between Artificial Intelligence in Education, Computer-Supported Collaborative Learning, Educational Data Mining, and Learning Analytics: a need for coherence. Frontiers in Education (Early access), 2020.

[15] Viberg O., Hatakka M., Balter O., Mavroudi A. The current landscape of learning analytics in higher education. Computers in Human Behaviour, v.89, 2018, pp98-110. DOI: 10.1016/j.chb.2018.07.027

[16] Berendt B., Vuorikari R., Littlejohn A., Margaryan A. Learning Analytics and their Application in Technology-enhanced Professional Learning. In Littlejohn A, Margaryan A, editors, Technologyenhanced Professional Learning: Processes, Practices and Tools. New York: Routledge. 2014. p. 144-157. (Advancing Technology-enhanced Learning). DOI: 10.4324/9780203745052

[17] U.S. Department of Education, Office of Educational Technology, Enhancing Teaching and Learning Through Educational Data Mining and Learning Analytics: An Issue Brief, Washington, D.C., 2012.

[18] Gillani N., Eynon R. Communication patterns in massively open online courses. The Internet and Higher Education, 23, 2014, 18-26.

[19]Elias T. Learning analytics: Definitions, processes, and potential. 2011. [online] [21.03.2021] Available at: http://learninganalytics.net/LearningAnalyticsDefinitionsProcessesPotential.pdf.

[20] Brown M., McCormack M., Reeves J., Brooks D.C., Grajek S. et al, 2020 EDUCAUSE Horizon Report, Teaching and Learning Edition (Louisville, CO: EDUCAUSE, 2020).

[21] Goldstein P. J., Katz R. N. Academic Analytics: The Uses of Management Information and Technology in Higher Education, ECAR Research Study Volume 8. 2005.

[22] McLelland D.C. Testing for competence rather than for "intelligence". American Psychologist 28(1), 1973, pp. 1-14. DOI: $10.1037 / \mathrm{h} 0034092$

[23] Boyatzis R.E. The Competent Manager: A Model for Effective Performance. Wiley, New York 1982.

[24] Prahalad C.K., Hamel G. The Core Competence of the Corporation. Harvard Business Review, 1990, pp. 79-91.

[25] Clarke N. The politics of training needs analysis. Journal of Workplace Learning, 15(4), 2003, pp. 141-153. DOI: $10.1108 / 13665620310474598$

[26] Zandbergs U., Grundspeņ̧⿻is J., Judrups J., Briķe S. Development of ontology based competence management model for non-formal education services. Applied Computer Systems 24(2), 2019, pp. 111-118. DOI: $10.2478 /$ acss-2019-0014 